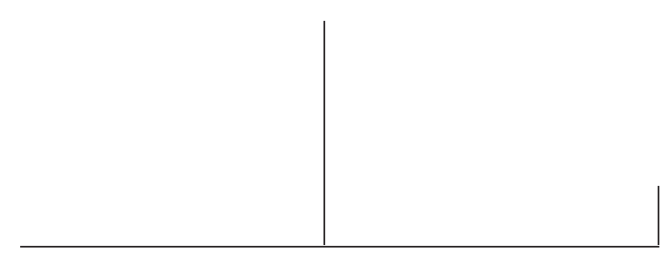

Rev. Latinoam. Psicopat. Fund., III, 1, 71-83

\title{
Oficina de marcenaria: uma experiência de criação de mundos*
}

\author{
Elizabeth Araújo Lima \\ Maria Inês Britto Brunello
}

O objetivo deste artigo é apresentar um trabalho desenvolvido com um grupo de adolescentes, com idades entre $12 \mathrm{e}$ 16 anos, com problemas emocionais graves, numa parceria entre o Curso de Graduação em Terapia Ocupacional da USP e a Pré-escola Terapêutica "Lugar de Vida”, do Instituto de Psicologia da USP.

Uma questão de fundo acompanhou o planejamento e a implantação deste trabalho: como se daria, para as crianças psicóticas a vivência do momento adolescente? Como poderíamos ajudá-las nesse momento de passagem, de abandonar a infância e preparar-se para uma travessia?

No grupo de terapia ocupacional nos propusemos a enfrentar essa questão, pesquisando e desenvolvendo junto com esses jovens um projeto que tinha como norteadores a implementação de uma maior circulação social e a pesquisa de possíveis relações com o universo da criação e da produção.

Palavras-chave: Adolescência, psicose, Terapia Ocupacional, atividades

\footnotetext{
* Apresentado no Congresso Internacional sobre Austimo e Psicoses Infantis, realizado em São Paulo, de 8 a 10 de agosto de 1997.
} 


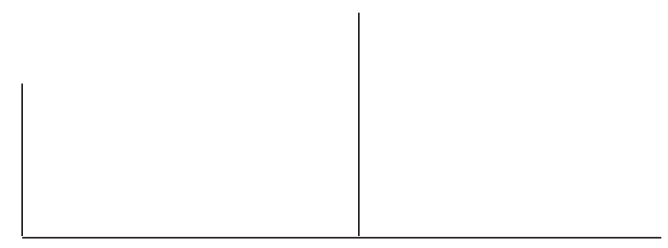

... o indefinido é a determinação do devir, sua potência própria, a potência de um impessoal que não é uma generalidade, mas uma singularidade no mais alto grau...

Gilles Deleuze

Em 1996, por nossa própria iniciativa enquanto docentes do Curso de Terapia Ocupacional da USP, iniciou-se uma experiência de parceria desse curso com a Pré-Escola Terapêutica Lugar de Vida, do Instituto de Psicologia da USP.

No primeiro contato com o Lugar de Vida buscamos pesquisar em que o curso de Terapia Ocupacional poderia colaborar com aquela experiência, já com seis anos de estrada. A resposta foi imediata: o Lugar de Vida é uma instituição organizada para atender crianças com problemas emocionais graves (Kupfer, 1996; p. 12). O que estava acontecendo é que essas crianças cresciam ou chegavam à instituição já próximas da adolescência, mas a equipe não tinha proposta de atenção para este outro momento da vida. ${ }^{1} \mathrm{O}$ pedido que a equipe nos fez foi o de pensar um projeto de oficina para atender esses, agora, adolescentes; uma oficina que pudesse prepará-los para alguma inserção no trabalho produtivo. Se o local de inserção social da criança é a escola, o do adulto é o trabalho/emprego. A adolescência, então, implicaria uma preparação para a vida adulta, na qual o trabalho desempenharia um papel fundamental. ${ }^{2}$

1. P. Ariés (1981) chama nossa atenção para o fato de "as idades da vida" serem, para o Ocidente, uma construção que tem suas raízes no final da Idade Média e ganha força e importância na Modernidade: "Na Idade Média, o primeiro nome já fora considerado uma designação muito imprecisa, e foi necessário complementá-lo por um sobrenome de família, muitas vezes um nome de lugar. Agora, tornou-se conveniente acrescentar uma nova precisão, de caráter numérico: a idade. O nome pertence ao mundo da fantasia, enquanto o sobrenome pertence ao mundo da tradição. A idade, quantidade legalmente mensurável com a precisão quase de horas, é produto de um outro mundo, o da exatidão e do número" (p. 30). Entre as "idades da vida" a adolescência só mais recentemente foi definida como um período intermediário entre a infância e a vida adulta: "Até o séc. XVIII, a adolescência foi confundida com a infância" (p. 41). O sentido contemporâneo de uma fase preparatória para a vida adulta precisa ser problematizado, já que a criação desta categoria imprime uma marca importante na forma como as subjetividades passam a se constituir.

2. "Para uma criança, o principal agente de inserção social é sem dúvida a escola (...) Assim, a reinserção escolar, no Lugar de Vida, é o alvo final, que equivale aos objetivos de diminuição do número de internações ou inserção no mercado de trabalho, usados pelos serviços de atendimento e hospitais-dia para adolescentes e adultos." (Kupfer, 1996; pp. 12-13) 


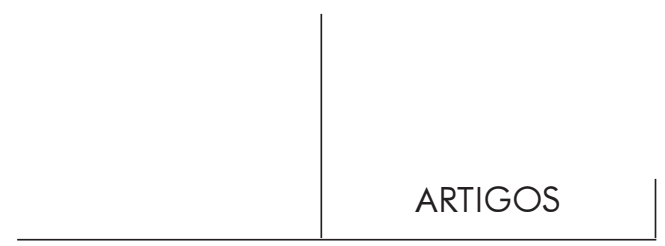

Estamos aqui às voltas com dois temas nos quais precisamos nos deter, antes de iniciar o relato de nossa experiência: o que é adolescência e como pensar o trabalho como instrumento da clínica em sua vertente de prática social.

\section{Adolescência: uma travessia}

Ao iniciarmos o atendimento dos jovens do Lugar de Vida estávamos mergulhados num caldo de questões que são os motores desse trabalho: o que é adolescência? Um momento de preparação para a vida adulta? O que diferenciaria a infância da vida adulta? Como se daria, para as crianças psicóticas, a passagem entre esses dois momentos (ou fases) da vida? Como podemos ajudá-las nessa travessia? Quais as possibilidades de vida que se abrem? É possível a criação de projetos de vida?

Podemos pensar que a adolescência se caracterizaria por ser um momento de crise, ruptura, rearranjos, reorganizações; momento de sensações de dissolvimento e indefinição, de busca de contorno, de busca de um "si-próprio"3.

Uma primeira aproximação dessas questões pode ser feita a partir de algumas indicações sugeridas por José Gil no Seminário que desenvolveu na PUC no ano de 1997. ${ }^{4}$ Aí, referindo-se à infância na poesia de Fernando Pessoa, Gil fez uma distinção para nós interessante: quando o adulto devém criança (como na poesia de Pessoa e seus heterônimos) um processo bastante diferente do devir-outro da criança ocorre. A plasticidade da experiência infantil decorre de a criança ainda não possuir um plano de consistência ${ }^{5}$. $\mathrm{O}$ devir-outro da criança seria a tentativa de criar esse plano de consistência; ela brinca de ser adulto na busca de um plano de consistência que não lhe é dado.

A partir dessas indicações, podemos pensar que na adolescência o sujeito estaria às voltas com a tentativa de construir esse plano de consistência, que permitiria a permeabilidade aos devires e o ingresso num processo de criação de si, sem que houvesse derrubamento, ruína.

Mas, para alguns sujeitos, a essas dificuldades inerentes ao processo, seriam acrescidas outras. Para adolescentes com história de autismo ou psicose na infância instalar-se num processo de diferenciação, individuação, criação de territórios próprios está, muitas vezes, dificultado, quando não impedido.

3. Para Gil (1987) é num devir que se chega a ser "si próprio": "O si próprio que então se devém é o sujeito plástico capaz de metamorfose" (p. 157).

4. "Multiplicidade e individuação na poética de Fernando Pessoa", Seminário promovido pelo Núcleo de Estudos e Pesquisas da Subjetividade da PUC-SP, durante o mês de setembro de 1997

5. J. Gil utiliza o conceito tal como Deleuze e Guattari o desenvolveram em Mil platôs: "superfície de inscrição de todas as intensidades" (1987; p. 84). 


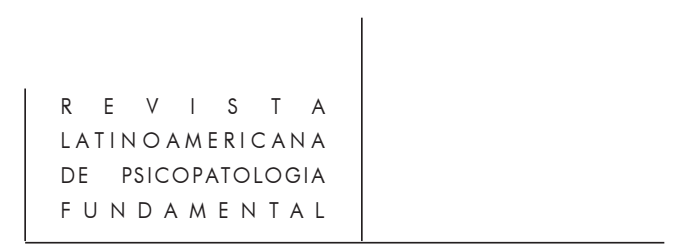

Isto porque estamos lidando aqui com processos de subjetivação que ocorrem marcados por uma diferença radical, por uma experiência de uma diferença desidentificadora que separa os sujeitos de si (Rolnik, 1995). A vivência dessa diferença muitas vezes gera paralisias e torna difícil a criação de novas formas de ser, aprisionando o sujeito no que Gil (1987; p. 65) chamou de inverso do plano de consistência: momento em que o plano de consistência ainda não foi construído: "Não é ainda um devir-outro, é já o fim do eu unitário. Este inverso do plano de consistência realiza uma consistência invertida: a suspensão total da vida".

Como, a partir de um tal estado, instaurar uma vivência de processualidade? Como transformar a sensação de indefinição em potência criadora de singularidades? Os territórios disponíveis no mundo da cultura são extremamente restritos, servindo mal àqueles que de alguma forma correspondem aos padrões correntes de modelização da subjetividade. Como criar territórios para além daqueles oferecidos pela família (o coletivo restrito ao qual, muitas vezes, a vida desses jovens está limitada)? Como transformar o próprio corpo num plano de consistência que dê sustentação às experiências desterritorializantes que começam a invadi-lo? Como introduzir produções culturais e artísticas em uma circulação coletiva, criando agenciamentos?

São muitas as questões, mas podemos pensar que o fato mesmo de nos fazermos essas perguntas já instaura um marco. Ao iniciarmos o atendimento desses adolescentes estávamos afirmando que um momento de transformações radicais estava se instaurando e que queríamos abrir portas e dar passagem para essas transformações, nos colocando em oposição à postura - tantas vezes presente no discurso de pais, terapeutas e educadores - de infantilizar esses sujeitos, tratá-los para sempre como crianças. A afirmação era: esses sujeitos não são bebês para sempre, eles estão crescendo, estão em processo.

Essa afirmação era particularmente importante para uma família que havia recentemente recebido um diagnóstico para sua filha de uma síndrome, o que era vivido como a negação de qualquer possibilidade de futuro.

Mas nossa idéia era afirmar o futuro como aberto. Mais que uma preparação para a vida adulta (concepção que traz em si a idéia de adolescência como período de normatização no qual a criança, ao crescer, deveria submeter-se às exigências do mundo adulto) passamos a ver a adolescência como um período de passagem, de travessia entre múltiplos estados, entre diferentes territórios, podendo vir a se constituir num platô $\hat{o}^{6}$. Queríamos acompanhar e facilitar esse processo por meio do Grupo de Terapia Ocupacional.

6. "Um platô não é nada além disso: um encontro entre devires, um entrecruzamento de linhas, de fluxos, ou uma percolação - fluxos que ao se encontrarem, modificam seu movimento e sua estrutura" (Jean-Clet Martin, in Mil platôs). 


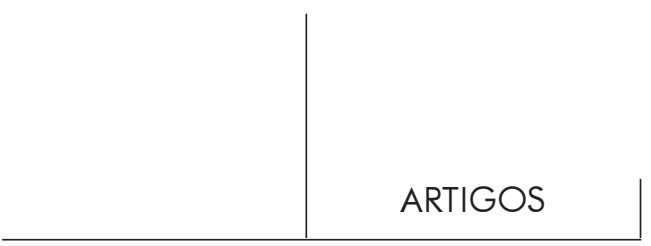

Entendendo a Terapia Ocupacional como um campo de investigação (Benetton, 1991), buscamos pesquisar e desenvolver um projeto tendo como norteador a implementação de um trânsito maior pelo social; maior autonomia em relação aos pais; circulação por espaços outros que não só o da família, e a pesquisa de possíveis relações com o universo da criação e da produção utilizando-nos, para tanto, de atividades que são nosso instrumento privilegiado.

Neste ponto seria necessário nos determos um momento para refletir sobre o trabalho como ferramenta clínica. Que sentido teria propor a esses jovens realizar atividades que não tivessem apenas um caráter de expressão, mas pudessem se constituir em experiências de produção de objetos com valor social?

\section{O trabalho: instrumento de uma clínica social?}

Abordar o trabalho produtivo como a única forma de inserção social do adulto, e pensar que na adolescência teríamos que preparar os jovens para esta inserção, é simplificar uma questão que nos parece bastante complexa e que merece ser abordada com atenção e cuidado. Não cabe neste momento discutir o lugar do trabalho na sociedade capitalista, o que nos tomaria muito tempo. No entanto, é importante apontar que, desde que a organização econômica passou a depender (o que já não é mais o caso) de contingentes cada vez maiores de mão-de-obra para a produção de riqueza, a noção de trabalho passou a ser encoberta por uma áurea de valorização. A capacidade de trabalhar passa, então, a ser considerada uma virtude que se opõe ao vício do ócio. ${ }^{7}$

Além de uma virtude o trabalho passou a ser tomado como medida de sanidade física e mental: saudável é aquele que trabalha. De um ou de outro modo, por um ou outro motivo, quem está fora do mercado de trabalho acaba fazendo parte do grande grupo de desviantes ou marginais, e deve ser de alguma forma reparado, como máquina quebrada, para a volta ao trabalho. O trabalho tem sido, assim, um importante instrumento de modelização; moldou e produziu a subjetividade do homem moderno, contribuindo de forma fundamental para a instalação e o desenvolvimento da sociedade disciplinar.

A Terapia Ocupacional, como profissão, nasceu nos Estados Unidos imersa nessa ideologia e tendo como centro de suas atividades a reabilitação profissional, em especial do deficiente físico. ${ }^{8}$

No entanto, estamos aqui abordando um tema espinhoso, repleto de contradições. Pois não é este, em absoluto, o caráter da intervenção na qual estamos

7. A esse respeito ver o panfleto de Paul Lafargue, "O direito à preguiça".

8. Léa B.T. Soares (1987), em Terapia ocupacional: lógica do capital ou do trabalho, analisa essas relações na realidade brasileira. 


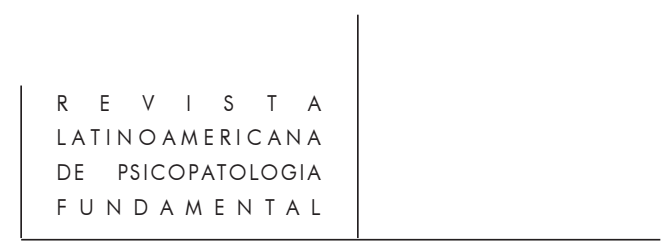

implicadas, mas se o trabalho tem sido um instrumento de modelização, tem, por outro lado, se constituído numa potente ferramenta de agenciamento coletivo, de construção de rede e de inclusão social.

Num período em que economistas e sociólogos discutem as conseqüências, seja para a organização social, seja para o sujeito e seus projetos de vida, do "fim do emprego" ou da "extinção do trabalho", é necessário pesquisar novas formas de exercício da capacidade produtiva e criativa dos sujeitos, sem desconsiderar que o trabalho, tal como o conhecemos, ainda é um forte instrumento de emancipação, ao engendrar valor de troca e propiciar a circulação, pelo tecido sociocultural, tanto do produto como de seu produtor.

Sendo assim, se o trabalho, tal como organizado na sociedade capitalista, é algo a ser discutido, questionado ou combatido, o é pela sociedade como um todo. Os usuários de serviços de saúde mental, assim como portadores de deficiências as mais diversas, devem ter, como todos os outros cidadãos, direito reconhecido de trabalhar e acesso ao universo produtivo. Experiências como as das Cooperativas de Trabalho ligadas a Instituições de Saúde Mental podem, inclusive, desembocar em novas formas de produtividade e de relação subjetiva com o trabalho, além de terem um papel extremamente importante no movimento de desinstitucionalização da doença e do doente mental.

Que pese o significado que tem, para cada um de nós, nossas produções e sua trajetória em um coletivo, seu valor de troca e de intervenção no universo cultural e social do qual fazemos parte.

Desta forma, não nos interessa nem aderir incondicionalmente a práticas de preparação para o trabalho, nem, por outro lado, descartá-las como um possível instrumento de uma clínica ampliada, mas sim problematizá-las. É preciso colocar em questão a redução, que muitas vezes se faz, ao se pensar a "inserção social" como adaptação a uma realidade dada ou a um modo dominante de existência e que não se procura modificar. Neste sentido, buscamos pensar o sentido último do trabalho clínico, em sua vertente de prática social, como criação de agenciamentos coletivos e de territórios compartilhados.

\section{O Grupo de Terapia Ocupacional: um espaço de experimentação}

Iniciamos o trabalho com um grupo de seis adolescentes (cinco meninos e uma menina), com idades entre 12 e 16 anos, num espaço diferenciado do Lugar de Vida, onde já participavam de atendimento há algum tempo. A idéia era marcar o início de um novo momento. O espaço utilizado era um laboratório de atividades do

9. A Folha de S. Paulo publicou, em seu Caderno "Mais!" de 3 de março de 1996, uma série de artigos reunidos sob o título: "Trabalho sem futuro, futuro sem trabalho". 


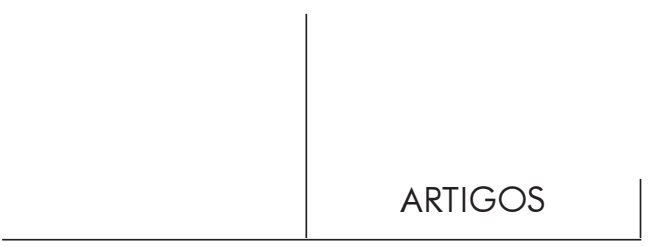

curso de Terapia Ocupacional, com bancadas, pias, ferramentas. Enfim, não um espaço infantil, mas um lugar preparado para trabalhar com outros adolescentes: nossos alunos do curso de graduação.

O fato de sairmos do espaço físico do Lugar de Vida e caminharmos para um outro lugar já imprimiu uma marca importante que, somada a uma outra marca, a da palavra "trabalho", fazia com que os adolescentes começassem a desenvolver uma postura, uma forma diferente de estar nesse espaço.

O primeiro tempo da experiência foi, então, um momento de reconhecimento de um novo lugar e de uma nova forma de trabalhar, de ampliação das relações, enfim, uma nova rotina se criava. Propusemo-nos a dar esse primeiro passo por meio da utilização de atividades variadas e diferentes materiais (tinta, argila, madeira, revistas, ingredientes de culinária) no sentido de investigar um foco de interesse por uma atividade comum ao grupo, um material com o qual pudéssemos trabalhar numa segunda fase. Nesta segunda etapa buscaríamos trabalhar com atividades mais estruturadas, onde o aprendizado de técnicas e o desenvolvimento de projetos com começo, meio e fim pudessem resultar em produtos com sentido coletivo. Produtos com utilidade e função social que pudessem de alguma forma circular coletivamente, cujo reconhecimento implicasse, também, um reconhecimento do sujeito que os produziu.

Entre os materiais que utilizamos nessa fase exploratória, a madeira foi o que mais pareceu mobilizar o grupo. Estranhamente, pois a madeira não é um material muito fácil de se trabalhar, mas, para a nossa surpresa, já da primeira vez que colocamos esse material à disposição, os participantes escolheram peças de madeiras, pregaram, cortaram, surgindo as primeiras produções.

Este movimento nos causou estranhamento e nos deixou maravilhados. Acreditamos que manter aberta a possibilidade de ser afetado e surpreendido pelo outro é essencial num processo terapêutico. Laznik-Penot (1992) nos mostra a importância, no trabalho com crianças autistas ou em estado pós-autístico, de nos deixarmos "siderar" por enunciados que a criança profere. Aqui, com uma "escuta que olha", nos maravilhamos também com a ação, o fazer desses jovens. Antes de começarmos a trabalhar com esse grupo tínhamos como objetivo possibilitar algo do surgimento do desejo, de algum movimento que partisse deles e que pudéssemos acompanhar. Agora nos encontrávamos ali quase que correndo atrás de um movimento que efetivamente surgia deles.

A madeira tinha se mostrado um elemento "propiciador para a construção de pontes. Pontes para si mesmo, pontes para o outro, pontes de madeira" (Mota, 1994; p. 95). Pontes, enfim, para facilitar as diversas travessias nas quais estavam implicados. (Fig. 1) 


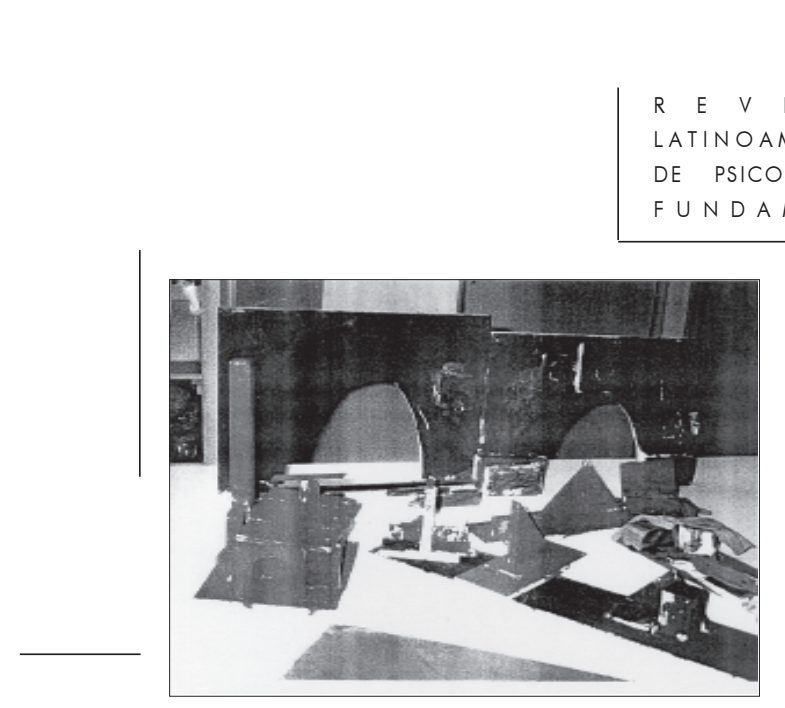

Fig. 1

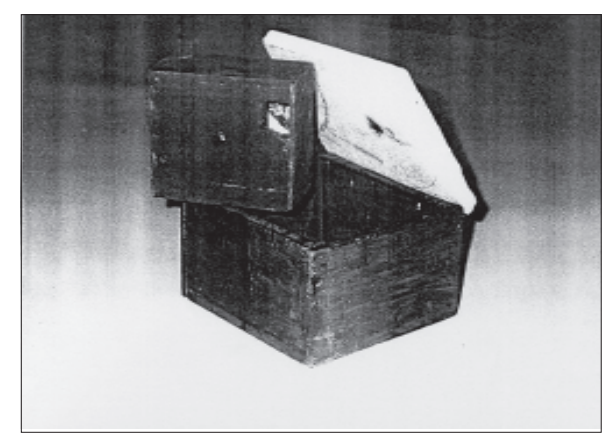

Fig. 2

\section{A Oficina de Marcenaria: um espaço de criação de mundos}

Com o início da Oficina de Marcenaria no semestre seguinte, o mesmo processo se repetiu: um fluxo de produção se estabeleceu e de início era quase impossível interferir nos projetos, na forma de execução ou ensinamento. Havia uma ânsia e um movimento ininterrupto, como se não houvesse um momento de idealizar e projetar, e o criar fosse se dando ali, a cada momento.

Desse movimento surgiram formas, algumas abstratas como objetos de arte contemporânea, outras que podíamos reconhecer e relacionar aos interesses de cada um. Aos poucos, quando íamos descobrindo, no próprio fazer, um movimento em direção a um certo objeto, íamos introduzindo a noção de projeto para trazer também uma noção de tempo; e o movimento ininterrupto ia dando lugar a um tempo mais processual.

É difícil dar uma idéia de como funciona a Oficina. Muita coisa acontece em cada dia. Uns dias são mais confusos, outros menos, mas sempre as coisas acontecem. Para muitos, chegar significa dar continuidade a um projeto: Pedrinho com seu caminhão; Welington com sua máquina fotográfica (Fig. 2); Fabiana com sua casa, que vai sendo recheada de recortes de revista a cada dia. Leo com seu caminhão, que nos parece exigir muito dele.

Não tem sido fácil, para Leo, realizar o que projetou. A madeira parece dura demais, os pregos entortam apesar de sua agilidade ao utilizar o martelo; as madeiras cortadas não se encaixam com a perfeição que talvez exigisse, mas continua na tarefa muitas vezes a duas vozes, suando e agitado. As madeiras vão se amontoando e a figura de um caminhão se esboça, vai surgindo. Apesar de toda a movimentação aparente, e de muito esforço e de toda energia que investe sobre o caminhão, o projeto nunca chega ao fim e Leo nunca descansa. 


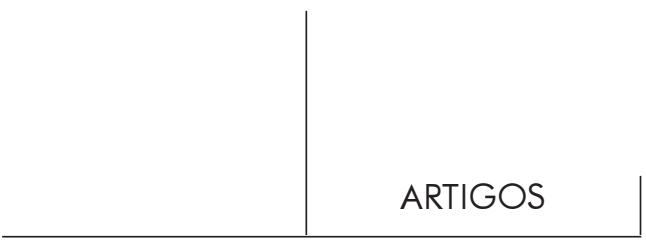

E a Oficina caminha assim. A cada dia novos retalhos de madeira são unidos dando forma a um carrinho, a uma caixa, a uma trave de futebol, a uma mesa, a um livro feito de recortes de revista colados sobre o retalho de madeira.

Pedrinho terminou um caminhão e um carrinho (Fig. 3). Foi um trabalho de muito investimento, pedia ajuda durante o projeto e se mostrava entusiasmado com o resultado que ia surgindo. Conseguiu projetar, organizar, criar, adaptar e realizar. Não via a hora de pintá-los. Não é de se espantar, seu pai é pintor de carros. Que estranha coincidência, será que ele está buscando uma referência no mundo adulto? Os trabalhos que Pedrinho realiza parecem ser, para ele, realmente muito importantes. Concentra-se no que faz, procura sempre a mesma bancada para trabalhar e lá fica durante a sessão inteira pregando, colando, serrando, procurando retalhos mais apropriados na caixa, pedindo a cola de madeira para quem estiver com ela.

Fabiana acabou (ou será que não?) a sua casa. Recortou figuras de revista coerentes com o tema do trabalho que vem realizando e os colou sobre a casa, fazendo questão de preencher seu interior. Diferente de Leo, Fabiana passa de um projeto a outro, desinveste de um e investe em outro, mas é sempre tempo de retornar ao primeiro e acrescentar coisas a ele; talvez ainda não esteja pronto. (Fig. 4)

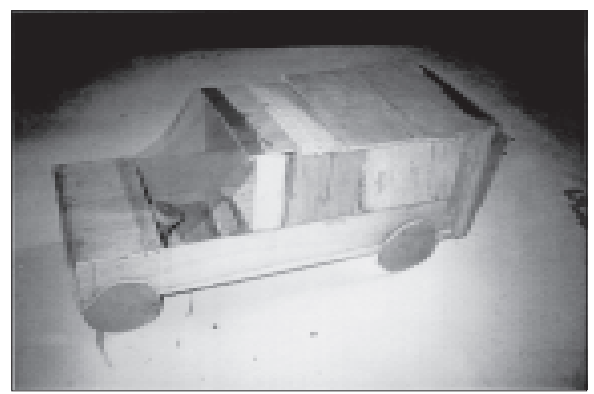

Fig. 3

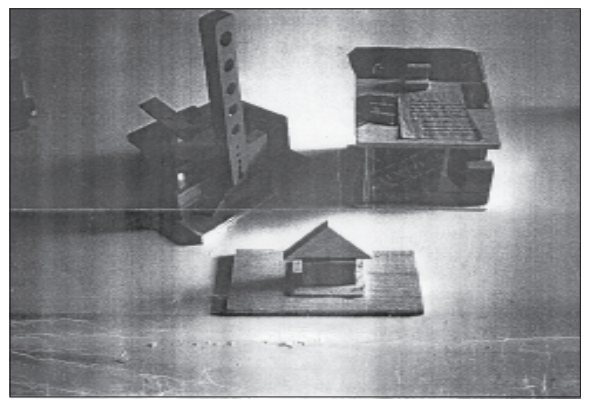

Fig. 4

Alex parece só se interessar por revistas que folheia incessantemente; é, então, a partir das revistas que vamos procurar trazê-lo para a marcenaria. Do movimento aparentemente sem sentido passa então a escolher algumas figuras para recortar e colar sobre a madeira. Faz, acompanhado, um livro com os recortes. Para ele, se desfazer dos recortes é muito difícil; então propusemos que construísse algo com os recortes, mas para além deles: montamos uma capa de madeira para que as folhas não amassassem e uma caixa para guardar os recortes. O importante é tentar trazê-lo para a proposta do grupo, para que, se deparando com algo novo, possa sair do movimento circular e interagir com o coletivo (grupo da marcenaria). Mas fica claro para nós que neste momento qualquer caminho que venha a se abrir será a partir das revistas. Se o mundo é tão excessivo de coisas desconhecidas que

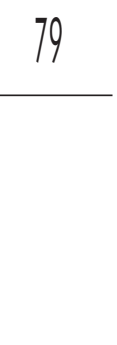




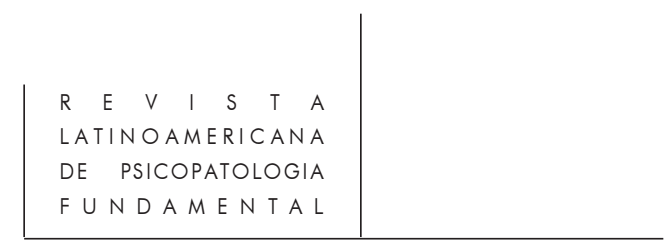

ele precisa voltar sempre ao mesmo ritual e fechar-se nele, vamos partir daquilo que parece menos ameaçador e, muito lentamente, tentar abrir portas e janelas para algo novo.

Para Carlinhos este lugar parece um espaço de satisfazer a "fome" - a fome de afetos, de contatos, de realizações e criações. Um fazer descontrolado, esfomeado e desordenado se transforma aos poucos num projeto e nesse movimento as formas vão aparecendo, ainda sem nenhuma palavra. (Fig. 5) Depois de um tempo neste fazer que parecia isolado, começa a olhar ao redor e inicia o projeto de um carrinho semelhante ao de outros colegas, projeto que é realizado em poucas sessões, como se a necessidade de vê-lo terminado fosse imperativa. É um desejo de se aproximar dos outros, de fazer parte de um grupo, que se materializa nesse carrinho? Estranhamente, ou talvez nem tanto, é nessa fase que começa a "falar" conosco, emitindo sons para pedir ajuda ou mostrar suas realizações.
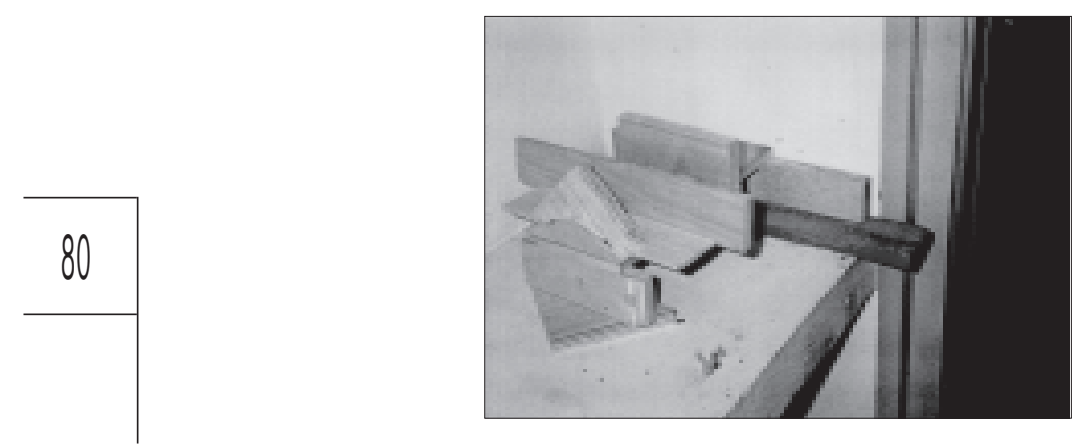

Fig. 5

Neste ponto seria interessante falar um pouco da constituição de um grupo que vai se dando no decorrer dos encontros. Embora a atividade proposta seja realizada individualmente, e cada um vá desenvolvendo um projeto próprio, interações e trocas começam a aparecer. Um trânsito de ferramentas e materiais se institui, assim como um olhar sobre a produção do outro. Em uma das oficinas Fabiana havia feito uma casinha e Carlinhos passou a desenhá-la na lousa.

Às vezes ver o trabalho do outro é causa de inveja: "Eu quero". Um pedido que pode ser respondido com o ato de presentear o outro, mas também com uma recusa que expressa uma apropriação daquilo que foi produzido.

Viviane Maximino (1997; p. 3) comenta, em sua tese de doutorado, que “... os grupos e as atividades realizadas na Terapia Ocupacional possuem uma 'potência de provocação", e, ainda, que os grupos funcionam como ampliadores do "potencial provocativo" das atividades. Ela está pensando em “"provocação' como aquilo que afeta, que conecta ambiente e órgãos do sentido, que é o resultado de algo que se liga e que já não é nem só ambiente nem só individual. A criatividade pode surgir 


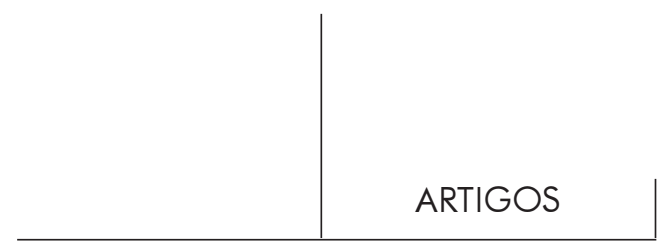

neste encontro com o material. O impulso produtivo necessita de uma materialidade - considerando a voz, os sons e os estímulos visuais também como materialidade para acontecer".

A madeira é um material que resiste àquele que lida com ela - umas são mais moles, outras mais duras -, mas sempre resiste às mudanças que buscamos lhe impor.

O que chamou a atenção neste trabalho foi o fato de essa resistência imposta pelo material não ter feito com que os jovens desistissem de trabalhar nos projetos. Percebíamos, na maioria deles, uma vontade de construção, de realização, mesmo com as dificuldades encontradas.

A construção com a madeira tem também a característica de introduzir o tempo no trabalho; exige um determinado projeto, um tempo que se estende de semana a semana, dando uma noção de continuidade, de processo, de vida em movimento. Ao final de um encontro, quando alguém quer levar algo que fez para casa, dizemos: "Ainda não está pronto, o que falta fazer? O que poderemos fazer da próxima vez?" Até que o trabalho esteja terminado e seja levado. É claro que o tempo de cada um é muito diferente: se Alex precisa a cada vez levar algo ao sair da oficina e seus projetos são imediatos, sendo-lhe muito difícil suportar a espera, Leo, ao contrário, não consegue finalizar e seu tempo se estende de tal forma que é como se não passasse e ele a cada vez se encontrasse no mesmo lugar, como Penélope que faz e desfaz seu manto para nunca acabá-lo. ${ }^{10}$

De qualquer forma, o fato de deixar algo inacabado faz com que a semana tenha dias, horas, minutos, tempo para esperar, elaborar, idealizar a próxima etapa, até chegar o próximo dia para que se possa dar continuidade ao inacabado, colocar mais peças sobre aquelas já organizadas e ir montando o quebra-cabeça do projetado - peça sobre peça até construir um todo a partir dos fragmentos.

A introdução de um projeto na atividade abre espaço para a idéia de um projeto de vida. Pedrinho começa a se perguntar: "O que eu vou ser quando crescer?". Para ele, a descoberta da sexualidade e da potência produtiva aparecem articuladas, como questões que estão implicadas nesse processo de crescimento, na sua travessia. Em um dos encontros ele abraçava uma terapeuta enquanto olhava seu trabalho em execução sobre a bancada; ao ser perguntado se tinha vindo ali para trabalhar ou para abraçar, respondeu: "Para trabalhar e abraçar".

Talvez nossa oficina de madeira seja um espaço de criação de mundos e de formas de estar vivo, de transitar pela vida, como intuiu um dos participantes do grupo quando disse: "Deus criou o mundo numa marcenaria". Estamos, assim,

10. Para Pelbart (1993), no trabalho com psicóticos seria preciso instaurar uma "espécie de cronogênese primordial, de onde pode surgir uma forma, até um projeto (p. 35). Uma cronogênese pode permitir que esses modos de temporalização diversos não sejam mais vividos no horror. Pode também abrir o acesso a um tempo onde haja começo, novo..." 
buscando pensar a inserção em atividades produtivas e de criação como instrumentos para promover a construção do plano de consistência ${ }^{11}$, a criação de territórios e de agenciamentos coletivos.

\section{Referências Bibliográficas}

Ariès, P. (1981). História social da criança e da família. Rio de Janeiro: Livros Técnicos e Científicos Ed.

Benetton, M.J. (1991). Trilhas associativas: ampliando recursos na clínica da psicose. São Paulo: Lemos.

Brunello, M.I.B. (1991). "Loucura: um processo de desconstrução da existência". Dissertação de mestrado. São Paulo, Programa de Psicologia Social da PUC-SP.

Deleuze, G. (1997) "O que as crianças dizem", in Crítica e clínica. Rio de Janeiro: Ed. 34. \& GuATTARI, F. (1996). Mil platôs: capitalismo e esquizofrenia, vol.3. Rio de Janeiro: Ed. 34.

GIL, J. (1987). Fernando Pessoa ou a metafísica das sensações. Lisboa: Relógio d’Água.

GuARÁ, I.M.F.R. (1997). "Modernidade, adolescência e cidadania", in Cidadania e subjetividade. São Paulo: Imaginário.

GuatTARI, F. (1992). Caosmose: um novo paradigma estético. Rio de Janeiro: Ed. 34.

KuPFer, M. C. (1996). "Apresentação da Pré-Escola Terapêutica Lugar de Vida”, in Estilos da clínica - Revista sobre a infância com problemas, ano I, nº 1: 8-17

Laznik-Penot, M. C.(1992). "O espanto do outro materno", in Boletim de Novidades da Livraria Pulsional, no 44, dez-92, São Paulo.

Lafargue, P. (1980). O direito à preguiça. São Paulo: Kairós.

LimA, E.A. (1997). "Clínica e criação: a utilização de atividades em instituições de saúde mental”. Dissertação de mestrado. São Paulo, Programa de Estudos Pós-Graduados em Psicologia Clínica da PUC-SP.

Maximino, V.S. (1997). "A constituição de grupos de atividade com pacientes psicóticos". Tese de doutorado. Campinas, Faculdade de Ciências Médicas da UNICAMP.

МотА, А.А. (1994). "A ponte de madeira: a possibilidade estruturante da atividade profissional na clínica da psicose". São Paulo, Sociedade Brasileira de Psicologia Analítica. Monografia de Conclusão da Formação.

Pelbart, P.P. (1993). A nau do tempo rei: sete ensaios sobre o tempo da loucura. Rio de Janeiro: Imago.

RoLNIK, S. (1995). "O mal-estar na diferença". Anuário Brasileiro de Psicanálise, 3: 97/103.

SoARES, L.B.T. "Terapia Ocupacional, lógica do capital ou do trabalho". Dissertação de mestrado. São Carlos, Programa de Pós-graduação em Educação da UFSCAR.

11. "O campo de imanência ou plano de consistência deve ser construído; ora ele pode sê-lo em formações sociais muito diferentes, e por agenciamentos muito diferentes, perversos, artísticos, científicos, místicos, políticos". (Deleuze \& Guattari, 1996; p. 19) 


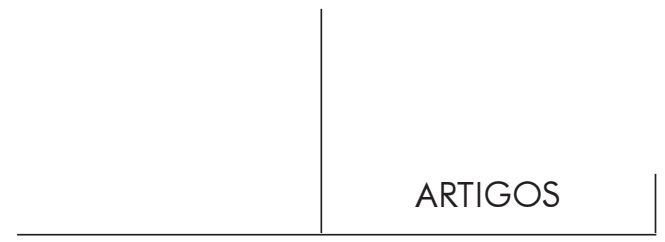

Resumos

El objetivo de este artículo es presentar un trabajo desarrollado con un grupo de adolescentes - con edades entre 12 y 16 años, con problemas emocionales graves - a través de un convenio entre el Curso de Graduación en Terapia Ocupacional de la Universidad de São Paulo (USP) y la Preescuela Terapéutica "Lugar de Vida”, del Instituto de Psicología de la USP.

Una cuestión de fondo acompañó la planificación e implantación de este trabajo: ¿cómo se daría en los casos de niños psicóticos la vivencia del momento adolescente? ¿Cómo podríamos ayudarlos en ese momento de pasaje, de abandono de la infancia y de preparación para una travesía?

En el grupo de terapia ocupacional nos propusimos enfrentar esa cuestión, investigando y desarrollando junto a esos jóvenes un proyecto que tenía como ejes la implementación de un tránsito mayor por lo social y el estudio de las posibles relaciones con el universo de la creación y de la producción.

Palavras llave: Adolescente, psicosis, Terapia Ocupacional, atividad

L'objetif de cet article est de présente um travail effetué avec un groupe d'adolescents de douze à seize ans, présentent des problémes émotionnels graves.

La préoccupation principale qui a accompagné le déroulement et l'èlaboration de ce travail était de savoir comment aider des enfants psychotiques à entrer dans l'adolescence; comment les aider dans cette phase à abandoner l'enfance et les préprare à vie d'adulte.

Dans le groupe de ergothérapie nous nous sommes proposé de regarder en face cette question, en recherchant et en développant avec ces jeune un project qui encourage la relation sociale, la création et la production.

Mots clés: Adolescents, psycotique, Èrgoterapeutic, activité

The aim of this article is to show a work developed with a group of adolescents from 12 to 16 years old, having serious emotional problems, in collaboration with the Occupational Therapy Graduate Course - USP and Therapeutic Preschool "Lugar de Vida", from the Psychology Institute - USP.

A fundamental question had a great importance in the planning and implanting of this work: how to explain life experience of adolescent moment to the psychotic children? How to help them in this moment of passing from childhood to adolescence and be prepared to this crossing?

In the Occupational Therapy group we decided to face this question, researching and developing together with this young people a project which had as guides the implementation of a greater transit across the social and research of possible relations with the universe of creation and production.

Key words: adolescents; psychotic; Occupational Therapy; activities 